\title{
Soberanía, elite política y espacios regionales en San Luis Potosí (1824-1828)
}

\author{
Barbara M. Corbett
}

Potosí aún ofrece en la suya, tal cual es hoy, recursos que aprovechados por un buen sistema político, económico, pueden muy en breve elevarlo a un punto de grandeza y abundancia muy respetable.

Manifiesto del Primer Congreso Constituyente del Estado de San Luis Potosí, 1824. ${ }^{1}$

\section{Introducción}

Si algo hemos aprendido de la historiografía del México decimonónico, sobre todo en los últimos diez años, es que el terreno más fructífero para el análisis de los grandes procesos históricos son las regiones; que el Estado nacional, objeto tradicional de historias político-económicas, era, al menos en la primera mitad del siglo, "una unidad de dominación ficticia". ${ }^{2}$ En mi proyecto de tesis, he tratado de seguir los consejos de Mario Cerutti, dejando que el objeto de mi estudio defina "lo regional". ${ }^{3} \mathrm{El}$ objeto de mi proyecto es analizar el proceso por el cual una elite política logra o no dominar los espacios regionales dentro de sus límites político-administrativos. En el caso del Estado nacional, sería hasta los años 80 que los espacios regionales "finalmente quedarían encerrados en el actual marco mexicano”. ‘ ¿Cómo y cuándo se da este proceso al nivel estatal?

El estado de San Luis Potosí presenta las características necesarias para tal análisis. Dentro de sus límites administrativos se encuentran dos espacios regionales bien marcados por sus actividades económicas. En este ensayo, veremos la configuración de estos ámbitos regionales, así como también la composición y trayectoria de la elite política del estado en los primeros años de la república. Viendo los principales ramos de producción - la minería y el tabaco-y las rentas que producían para el estado, podemos empezar a entender lo difícil que era para la elite política aprovechar los recursos de su estado. El mismo sistema fiscal dejaba espacios para la acumulación privada, que en una economía de poco numerario, eran escapes de capital esencial para los proyectos de la elite política. Y cuando esa elite intentaba intervenir en aquellos espacios, su política fiscal se volvía eje de conflicto político.y social. ¿Será posible que el estado de San Luis Potosí de los años 20, los meros años del florecimiento del federalismo, haya sido también una entidad de dominación ficticia?

\footnotetext{
1 Enrique Márquez, comp., San Luis Potosí. Textos de su historia, Instituto Mora, México, 1986, p. 22. Las cursivas son mías.

2 Juan Felipe Leal, La burguesia y el Estado mexicano, Ediciones El Caballito, México, 1972, p. 57.

${ }^{3}$ Mario Cerutti, "Monterrey y su ámbito regional (1850-1910). Referencia histórica y sugerencias metodológicas", UANL, Monterrey, mimeo., 1989, p. 8.

${ }^{4}$ Ibid., p. 2.
} 


\section{Dos ámbitos regionales}

Los geógrafos suelen dividir el estado de San Luis Potosí en seis zonas geográficas que ascienden de la llanura costera de la Huasteca en el oriente hasta los altos del Zacatal en el oeste. ${ }^{5}$ Los historiadores, siendo más reduccionistas, solemos dividir el estado en dos grandes ámbitos regionales que se dan en torno a la ciudad de San Luis Potosí (el Altiplano) y al puerto de Tampico (la Huasteca y la cuenca del río Verde). ${ }^{6}$ Esta división se debe mucho a diferencias topológicas, geológicas y hasta climatológicas. El altiplano rocoso, de suelo metálico, de clima seco y templado contrasta con los suelos fértiles de la cuenca del río Verde y la Huasteca, cruzados con ríos y lagunas, de un clima más bien caliente y abundantes lluvias.

En el altiplano, los españoles desarrollaron un complejo minero prototipo del centro-norte de México, pueblos mineros abastecidos por grandes haciendas ganaderas y pueblos de indios tlaxcaltecas. Siendo todavía parte de la Nueva España, la ciudad de San Luis tenía. muchas relaciones comerciales con México. De San Luis salían las barras de plata y oro para la Casa de Moneda en México; también sebo y lana para las fábricas de Querétaro en donde eran procesados y mandados al gran mercado de México. Comerciantes de la ciudad de México tenían tiendas en los pueblos mineros de Potosí, mientras los dueños de minas y haciendas potosinas muchas veces tenían sus residencias en México. No obstante estos nexos, el complejo minero de San Luis Potosí encuadra mejor como parte integral del centronorte de México, que ocupaban Zacatecas, Guanajuato, Querétaro, partes de Jalisco y Durango. Las minas de San Luis, sobre todo las del Real de Catorce, mandaban su plata y oro a la Casa de Moneda en Zacatecas. Los centros mineros de Guanajuato, Zacatecas y Pachuca dependían de las sales, tequezquite, sebo y lana que les llegaban de San Luis. Productos potosinos también abastecían las provincias de Nuevo León, Coahuila, Texas y Nuevo Santander (Tamaulipas), que hasta 1822 formaban parte de la gran Intendencia de San Luis Potosí. Y por los caminos reáles entre San Luis Potosí, Zacatecas, Sombrerete, Durango y Guadalajara llegaban los comerciantes a la feria de San Juan de los Lagos, la feria más grande del norte a finales de la época colonial. ${ }^{7}$

Del complejo minero del altiplano de San Luis, surgió una sociedad hispanizada, fuertemente dividida en castas sociales. La elite colonial eran los mineros y hacendados, muchos de ellos de origen vasco, como en otras partes del centro-norte. ${ }^{8} \mathrm{~A}$ diferencia de sus análogos en ciudades centrales como Puebla o Valladolid, la elite potosina se distinguía por la presencia de los militares y la ausencia de una administración eclesiástica. Como la amenaza de una invasión de chichimecas era vigente en San Luis a lo largo del periodo

${ }_{5}$ Octaviano Cabrera Ipiña, Monografía del estado de San Luis Potosí, Imprenta Universitaria, San Luis Potosí, 1985, p. 20.

6 Márquez, op. cit., ilustra muy bien lo que él llama "esa dualidad histórico-regional" (p. 13).

7 Para más sobre la economía minera del centro-norte, véase D.A. Brading, Mineros y comerciantes en el México borbónico (1767-1810), F(.F., México 1975. Sobre la feria de San Juan, véase Manuel Carrera Stampa, "Las ferias novohispanas", Historia Mexicana, vol. 2, 1952/3:319-42).

s Brading, op., cit., p. 150. 
colonial, los militares españoles habían figurado entre las primeras filas de su elite. En cuanto a la Iglesia, la ciudad de San Luis no era una diócesis eclesiástica, formaba parte de la de Valladolid. He aquí la debilidad relativa de la Iglesia en San Luis. ${ }^{9}$ Con la caída en la producción de la minería a finales de la Colonia y la escasez del crédito, los comerciantes empezaban a entrar en los núcleos elites. Entre los alcaldes del ayuntamiento de la capital en los años 1800-27, destaca la presencia de los comerciantes, tanto criollos como españoles (apéndice A). Como en las ciudades del centro de México, los hijos criollos solían volverse militares o curas, pero también en el centro-norte había oportunidades en el comercio y la burocracia. En las filas bajas del ejército y la Iglesia, la gente mestiza podía entrar, pero muchos de ellos escogían carreras como artesanos, empleados o arrieros. Finalmente había los indios de los pueblos abastecedores, quienes no tenían muchas opciones fuera de ser peones o jornaleros en las haciendas. Entre las haciendas y los pueblos existía una "explotación simbiótica" que ayudaba a mantener el control social. ${ }^{10}$

Otro mundo era la parte oriente del estado, separada del altiplano por unas montañas formidables. Allí, donde no encontraban metales preciosos, sino pueblos otomíes, pamis, huastecos y nahuas, los españoles formaron enormes estancias ganaderas y la institución de la encomienda. Aunque hay evidencia del cultivo de caña en la época colonial, incluyendo el uso de esclavos africanos, no había desarrollo agrícola en gran escala. " El criollo Felipe Barragán, dueño de gran parte del oriente de la provincia a finales del siglo XIX, hizo su fortuna en el comercio, llevando barras de plata de Catorce y México vía el Valle del Maíz y Querétaro. ${ }^{12}$ Desde principios del siglo, esta región empezó a orientarse al puerto de Tampico y su comercio clandestino con Louisiana. De Tampico salían plata, pieles, maderas, azúcar, café, tabaco y otros productos de las Huastecas y entraban harina, plomo, alquitrán y otras "mercancías", incluyendo armas, de Estados Unidos. ${ }^{13}$ Era este comercio el que convenció a Humboldt en 1803 de las posibilidades del desarrollo de la región, sobre todo para el cultivo de algodón y la exportación de ganado. La visión humboldtiana influiría a más de una generación de potosinos del

9 Moisés González Navarro, Anatomía del poder en México, 1848-53, El Colegio de México, México, 1977, pp. 88-89. Era una debilidad relativa a los aparatos burocráticos y administrativos de Puebla o-Valladolid. Pero los eclesiásticos en San Luis Potosí también tenían mucha propiedad urbana y sus conventos y cofradías también funcionaban como fuente de crédito para hacendados potosinos. Para el papel de la Iglesia en la economía colonial mexicana, hay que ver Nancy M. Ferris, Crown and clergy in colonial Mexico, 1759-1821, London, 1968.

10 El concepto de la "explotación simbiótica" es desarrollado a lo largo de John Tutino, From insurrection to revolution in Mexico: social bases of agrarian violence, 1750-1940, Princeton University Press, Princeton, 1986, p. 234.

1 Mari-Jose Amerlinck de Bontempo, "From hacienda to ejido: The San Diego de Rio Verde Case", Ph. D. Dissertation, State University of New York at Stonybrook, December 1980 , p. 87.

12 Enrique Márquez Jaramillo y Horacio Sánchez Unzueta, El fraccionamiento de las tierras de Felipe Barragán en el oriente de San Luis Potosí, I797-1905, Academia de Historia Potosina, serie Cuadernos 83, San Luis Potosí, 1984, pp. 2-12.

13 No hay muchos trabajos sobre el comercio Tampico-Louisiana al principio del siglo xix. Dos artículos útiles, aunque ya viejos, son Alfred Toledano Wellborn, "Relations between New Orleans and Latin America, 1810-1824", Louisiana Historical Quarterly, vol. 22/3, July 1939, pp. $710-794$ y Lauro A. de Rojas, "A consequence of the Louisiana purchase", Louisiana Historical Quarterly, vol. 21/2, April 1938, pp. 362-366). 
orientè. ${ }^{14}$ Sin embargo, en vísperas del grito de Hidalgo, había poco desarrollo dadas las dificultades en comunicación y transporte para no hablar de las amenazas de la fiebre amarilla.

Allí, el núcleo de la elite colonial era el puñado de grandes comerciantes/hacendados como Felipe Barragán y la familia Moctezuma Ortiz de Zárate. Como eran propietarios ausentes, sus administradores tenían mucho poder también. Con la formación del ejército real de Calleja, los militares criollos del oriente llegaron a ser dueños de haciendas y rancho, y tener puestos en la burocracia virreinal. Aunque formaba parte del obispado de México y había unas misiones del Fondo Piadoso de las Californias, la presencia eclesiástica en Río Verde y la Huasteca era muy poca. ${ }^{15}$ "Confesarse en artículo de muerte", comentó un alcalde de la Huasteca en 1825, "no hay ya quien lo piense". ${ }^{16}$ La clase media del oriente eran los rancheros, arrendatarios, y condueños; había pocos peones de hacienda. ${ }^{17} \mathrm{Tam}$ poco había gremios de artesanos, pero los arrieros abundaban. La mayoría de los indios del oriente vivían en sus pueblos donde mezclaban economías de subsistencia con un comercio interno bastante activo. Estos pueblos se parecen a las comunidades permeables que encontró Nancy Fariss en Yucatán. Como en el sureste de Yucatán, los pueblos de la Huasteca eran refugios para indios y esclavos que escapaban de las plantaciones y minas. ${ }^{18}$ En general, el terreno social era más complejo y las divisiones de clase más permeables en el oriente que en el altiplano. La elite no controlaba fácilmente a sus peones, a sus arrendatarios ni a los pueblos indígenas. Las autoridades locales dependían mucho del azote.

\section{La elite altiplana}

¿Quiénes heredaron el gobierno de San Luis después de la independencia? Durante los años turbulentos de 1821-23, la provincia de San Luis Potosí fue "gobernada" por una serie de comandantes militares - todos ex oficiales del ejército real de Calleja-y por su jefe polí-

14 Alexander von Humboldt, Political Essay on the kingdom of New Spain, London, 1811, vol. II, pp. 271-281. La influencia de Humboldt se anota en José Florencio Barragán, "La provincia de San Luis Potosí en el reino de Nueva España (1814)", en Enrique Florescano e Isabel Gil Sánchez, comps., Descripciones económicas regionales de Nueva España. Provincias del norte, 1790-1814, SEP-INAH, México, 1976.

${ }^{15}$ Memoria del estado de San Luis Potosí, 1828, Imprenta del Estado, San Luis Potosí, 1829, cuadro 2.

16 Archivo Histórico del Estado de San Luis Potosí (AHESLP), Secretaría General de Gobierno (SGG), 1825, legajo 8-C, cuadro estadístico de la Villa de Santiago de Valles.

17 Condueñazgo es una forma de tenencia de la tierra en las Huastecas que surgió en el siglo XIX. "Extraña derivación de la merced y la hacienda, ese régimen permitió que varias generaciones de herederos conservaran indivisos los terrenos que habían pertenecido a una sola persona." Enrique Márquez, "Formación y naturaleza de feudos y caciques", en Márquez, op. cit., p. 405. Unos condueñazgos fueron formados por las familias Noriega y Ortiz de Zárate en 1827 en sus haciendas de Amolederas y Ciénega de Cárdenas. Ofrecieron "dar" parcelas de tierras a indios a que las trabajaran en común, pero sin permiso para enajenarlas jamás. AHESLP, SGG, 1827, legajo diciembre-1, "Expediente instruido por este Gobierno sobre la fundación del nuevo Gamotes". Sobre arrendatarios y peones, véase Bazant, op. cit.; Márquez y Sánchez, op. cit.

is Nancy Fariss, Maya society under colonial rule: the collective enterprise of survival, Princeton University Press, Princeton, 1984. De la Huasteca como refugio, véase Peter Gerhardt, $A$ guide [to] the historical geography of New Spain, Cambridge University Press, Cambridge, 1972, pp. 234-39 y 354-59. 
tico, el licenciado Ildefonso Díaz de León, un rico comerciante. Cuando la provincia se volvió estado en enero de 1824, todavía los mulitares criollos y los comerciantes llevaban el timón.

El comandante general era el general Gabriel Armijo, quien había sido jefe de las tropas realistas del sur en las campañas contra Guerrero. Al mando de la comisaría general (la ex intendencia) estaba otro militar realista, el teniente coronel Antonio María Esnaurrízar. Hijo del tesorero de las Cajas Nacionales de Zacatecas, Esnaurrízar también había ocupado varios puestos en la Hacienda bajo Calleja e Iturbide, incluyendo el de administrador de tabacos de San Luis y contador de aduanas. ${ }^{19} \mathrm{El}$ capitán Manuel Sánchez fue nombrado administrador de aduanas del estado en 1824. Por todos los rincones del estado, los ex militares realistas manejaban la administración y recaudación de impuestos, cosa que tendría consecuencias importantes para la elite política del estado en los años 20, y después.

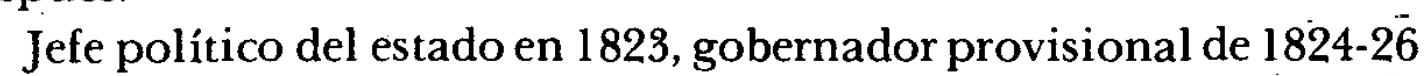
y primer "gobernador constitucional" en 1827, Ildefonso Díaz de León era un criollo de Sierra de Pinos en Zacatecas. Como muchos otros comerciantes criollos, hizo su fortuna en el auge minero de 1780-90, traficando en el centro-norte con barras de plata, azogue, sal, sebo y lana. Las redes de los comerciantes potosinos más establecidos llegaban hasta México, Veracruz y aun a Cádiz. ${ }^{20}$ Con la caída de la producción minera a principios del siglo y la escasez del capital, estos comerciantes acumularon capitales, haciendo préstamos a cambio de hipotecas sobre fincas urbanas o rurales. Asi, muchos hacendados perdieron sus bienes. También los comerciantes hicieron sus préstamos al gobierno del estado a cambio del control de las rentas más productivas. ${ }^{21}$ Cuando Díaz de León se casó a principios del siglo, llevaba a su matrimonio "un capital" de 30000 pesos, una cantidad considerable. Ya por 1827 , sus bienes valían mucho más, incluyendo una casa de comercio en Catorce, la hacienda de Charcas de Cañada, una hacienda de beneficio de metales en Matehuala, una casa en el centro de San Luis y otras fincas urbanas. En este entonces el gobernador pudo declarar: "a nadie soy deudor de cosa alguna". ${ }^{22}$ Como notó Tutino en una obra reciente, para algunos grupos "la desintegración puede ser tanto creativa como benéfica". ${ }^{23}$

19 AHESLP, protocolos de Instrumentos Públicos, 1822. José de Esnaurrizar, padre de Antonio María de Esnaurrízar, aparece en varios documentos como tesorero de las Cajas Nacionales de Zacatecas.

20 Por medio de los docúmentos de los apoderados, sobre todo los que hacían los comerciantes dando poderes de cobranza, se puede reconstruir la red comercial de este grupo. Entre los comerciantes con lazos en México y Veracruz se encuentran los españoles, Andrés Pérez Soto (quien también tenía apoderado en Cádiz. AHESLP, protocolos de Inst. Púb., 1822; 1824:360-62) y Martin Muriel (protocolos de Inst. Púb., 1822:292), y el criollo Isidoro Puente Robledo (AHESLP, protocolos de Inst. Púb., 1826:603).

21 Rafael Villalobos, capitán realista durante la guerra y uno de los comerciantes más ricos de la capital, administraba las rentas reales de pólvora y tabacos en SLP en 1820. En 1827 heredó el arrendamiento de la matanza de ganado por medio de una hipoteca. Su hermano Eulogio Arias arrendaba la corrida de toros en 1824. Juan Guajardo, primer tesorero del estado en 1824, compraba el asiento de gallos en remate en 1823. AHesl.P, protocolos de Inst. Púb., 1823:92; 1824:408; 1827:8-10, y 1823:157.

22 El testimonio de Díaz de León, AHESLP, protocolos de Inst. Púb, 1827:43-46.

23 Tutino, op. cit., p. 217. La traducción es mía. 
La composición de los primeros congresos del estado de San Luis Potosí nos dice mucho de su elite política (apéndice B). En primer lugar, todos eran mexicanos, no había ningún peninsular. También se anota la presencia de unos abogados y militares politizados e "ilustrados", cuyas ideas sobre el desarrollo económico del estado contenían unos aspectos plenamente burgueses. ${ }^{24} \mathrm{Su}$ influencia se dejó sentir sobre todo en la legislación sobre el fomento de la agricultura, poniendo en tela de juicio los privilegios tradicionales de hacendados y eclesiásticos. El decreto 22 de 1826, por ejemplo, obligó a los propietarios a arrendar las tierras que no podían cultivar solos. Otras leyes "ilustradas" incluyeron las que dejó en manos del estado la recaudación de diezmos, reguló los contratos de arrendamiento de tierras, abolió la esclavitud y prohibió el servicio personal de indios. ${ }^{25-}$ Veamos, por ejemplo, el dictamen de la comisión especial del Congreso Constituyente de 1826, encabezado por el coronel José Miguel Barragán, sobre un proyecto de dividir propiedades eclesiásticas en el oriente:

Terrenos inmensos en pocas manos no se cultivan. La clase laboriosa sujeta a muy cortos jornales, a subidas rentas o a contratos desventajosos, no puede empeñarse mucho. Cuando se dividan las grandes posesiones y hagan muchos propietarios; cuando la formación de sociedades ilustradas auxilien con sus conocimientos y recursos a los que carecen de ellos; cuando gravosas contribuciones no hagan sentir su peso a los labradores; en fin, cuando la educación destierre la pereza a que nuestros conquistadores nos habituaron, entonces saldrá la agricultura del infantil estado en que la vemos, pues ahora apenas comienza a hacer algunos esfuerzos, que al fin serán infructuosos $\sin$ aquellas medidas. ${ }^{26}$

Esta corriente progresista fue templada por los otros diputados, representantes de los principales núcleos de la elite del altiplano (comerciantes, hacendados, eclesiásticos y militares). Díaz de León era capaz de hacer de esas diferentes corrientes una sola política. El fomento de la agricultura desempeñaria un papel secundario al fomento de la minería y la industria. En 1824 la legislatura estableció una fábrica de tabaco, y declaró el establecimiento de una casa de moneda en 1825. Facilitó la entrada de capital extranjero, principalmente británico, en el sector minero, mientras que sobre la mercancía importada impuso una serie de gravámenes. Así, la elite política esperaba tener un monopolio sobre todas las actividades económicas en su territorio.

Pero para poder realizar su proyecto económico, el gobierno del estado necesitaba fondos. Desde sus inicios en la diputación provincial, entre 1821-24, la elite política había dependido económicamente de grupos conservadores. Éstos incluían los ayuntamientos de la capital y de los centros mineros, la diputación de minería, la Iglesia y los comerciantes. Esta dependencia se ve claramente en el conflicto sobre pago de dietas entre 1821-24. En noviembre de 1821,

${ }^{24}$ Para comparar la "corriente en ciernes" en Jalisco con el grupo en San Luis, véase Antonio Ibarra, "Jalisco en la primera mitad del siglo XIX", tesis de maestría, Facultad de Economía, Universidad de Guadalajara, Guadalajara, 1986, p. 8.

${ }^{23}$ La colección completa de las leyes de los primeros congresos se encuentra en Legislación Potosina, vol. I, Imprenta de la Escuela Industrial Militar, San Luis Potosí, 1892.

${ }^{26}$ Márquez, op, cit., p. 28. 
Iturbide declaró que la responsabilidad de pagar las dietas de las delegaciones congresistas la tenían las diputaciones provinciales. ${ }^{27}$ Para poder pagar estas dietas, la diputación de San Luis tenía que recurrir a los pueblos del estado, porque "no reconocía por fondos para sus gastos más que los sobrantes de las municipalidades". ${ }^{28}$ Después de varios intentos fútiles de crear nuevos impuestos municipales, la diputación tenía que pedir prestado más de 5000 pesos del ayuntamiento de la capital, l 100 pesos de los ayuntamientos de Catorce y Santa María del Río, y 2300 de varios comerciantes de la capital. ${ }^{29}$ Juntos, los diputados y los miembros de estos grupos conservadores constituían la crema y nata de la sociedad potosina en los años 20. Eran miembros de la junta parroquial de la capital, contribuían al Colegio Guadalupano, controlaban la administración de hacienda y todos los puestos políticos más importantes del estado. ${ }^{30}$ Por sus diferencias políticas y los conflictos fiscales, la alianza entre la elite política y los grupos conservadores tenía un carácter tenue. Sin embargo, estaba basada en la visión común de un monopolio de producción y comercio estatal, fundado en la minería y complementado por la industria y la agricultura, todo ello dirigido desde el altiplano.

\section{"Una pistola cargada"}

¿Cómo se constituía la constelación de intereses que era Tampico en los años 20? El núcleo de este espacio regional -que incluía el oriente de San Luis Potosí, el sur tamaulipeco, el norte de Veracruz y el noroeste de Hidalgo - eran los comerciantes extranjeros no españoles (aunque había unos españoles importantes también). Entre este grupo, la presencia dominante eran los norteamericanos. ${ }^{31} \mathrm{Va}$ rios de ellos tenían sus residencias en la capital de San Luis, pero sus negocios los tenían en Tampico y Catorce. La mayoría de los barcos que llegaban a Tampico en estos años salían de Nueva Orleans, cargados de mercancía tanto europea como estadunidense. ${ }^{32}$ Hay muchos índices de que las ganancias principales de este puñado de comerciantes venían del contrabando. En 1822, la diputación provincial se quejaba de "los perjuicios que resultan a la industria nacional del comercio libre de los efectos que los angloamericanos han introducido y continúen introduciendo por el puerto de Altamira". ${ }^{33} \mathrm{En}$

27 Charles W. Macune, Jr., El Estado mexicano y la federación mexicana, $1823-$ 1835, FCE, México 1978, p. 59.

28 AHESLP, SGG, 1826, legajo agosto. Representación del Congreso Soberano al Tesorero del Estado sobre pago de préstamos.

${ }^{29}$ Los intentos de la diputación para recaudar fondos y los repuestos de los pueblos se ven en los libros 7, 9-12, de Sesiones de la Diputación Provincial en AHESLP, Intendencia, 1822, legajo 3; 1823, legajos 5, 6, 7; SGG, 1824, legajo 8 .

30 AHESL.P, SGG, 1824, legajo 1; 1826, legajo junio-1, junio-2.

31 Hasta la arquitectura era reflejo de la influencia norteamericana. Véanse las observaciones de Madame Calderón de la Barca en Frances Calderón de la Barca, Life in Mexico, J.M. Dent \& Sons, London, 1913, 1960, 2a. ed., p. 534: "I could have fancied miself in a New England village: neat 'single palaces', with piazzas and pillars nothing Spanish ... We afterwards heard that these houses were actually made in the United States and sent out here."

32 Inés Herrera Canales, El comercio exterior de México, 1821-1875, INAH, México, 1977 , cap. IV.

33 AHESLP, Intendencia, 1822, legajo 3, "Libro 7 de las Sesiones de la Diputación Provincial", sesión 3 de septiembre, 1822. 
este mismo año Poinsett se sorprendió del número de comerciantes paisanos suyos que vivían en San Luis. ${ }^{34} \mathrm{La}$ orden presidencial de abril de 1825 que prohibía a los administradores aduaneros revisar a los extranjeros en las garitas alcabalatorias, era un estímulo más para la entrada y salida del contrabando. Sobre todo porque entre el puerto de Tampico, que no tenía aduana marítima hasta 1827 , y la ciudad de San Luis, donde la mercancía pagaba sus derechos de internación, había una larga distancia de 104 leguas. La frecuencia de pleitos legales entre comerciantes extranjeros y administradores de aduanas también sugiere la participación de aquéllos en el tráfico clandestino. ${ }^{35}$ La denuncia formal que hizo Díaz de León en mayo de 1825 al secretario de Hacienda sobre el diluvio de "mantas extranjeras" entrando en el estado por el río Pánuco y causando la ruina de su industria, no parece haber tenido ningún efecto. ${ }^{36}$ Todavía en 1826 los administradores de rentas de la parte oriente del estado comunicaban al gobernador "los fraudes que hacen los extranjeros comerciantes, que se han radicado en la Villa de Valles y otros puntos del estado". ${ }^{37}$ Aun las casas comerciales británicas en Tampico expresaban su preocupación por la mercancía barata introducida al puerto por los comerciantes norteamericanos. ${ }^{38}$

Los comerciantes extranjeros tenían sus apoderados mexicanos que les servian de representantes. Los hermanos Didier de Baltimore tenían como dependiente en Catorce a Francisco Xavier Martín; su apoderado en la ciudad de San Luis era Domingo Urtegui. Ignacio Eguía, descendiente de una familia vasca minera muy importante en Zacatecas y miembro de la diputación de minería en San Luis, era un apoderado de Carlos Mirick de Nueva York. Cayetano Rubio, quien se convertiría en uno de los más notorios agiotistas de los 30 , era apoderado de Francisco Battle y Pascual, un comerciante en Tampico, "residente en Génova". ${ }^{39} \mathrm{El}$ comerciante español Tomás del Hoyo, residente respetable de la capital y gran contrabandista, también tenía relaciones en Tampico con casas de comercio extranjeras. ${ }^{40}$ Estos representantes locales no formaron parte de la elite política del altiplano; no aparecen ni en el Congreso del estado ni en el ayuntamiento de la capital.

Como no tenían un cuerpo político para hacer manifiestos, no podemos hablar de la trayectoria de esta elite. Suponemos que los norteamericanos eran librecambistas y simpatizantes de la logia yorkina. No faltaban comerciantes del altiplano quienes, sin compartir ideología ninguna con los "anglo-americanos", estaban dispuestos a ser colaboradores. Y también para encontrar colaboradores, el

34 Jan Bazant, Cinco haciendas mexicanas: tres siglos de vida rural en San Luis Potosí, El Colegio de México, México, 1975, p. 35.

35 AHE.SLP, protocolo de Inst. Púb., 1822-28.

36 AHESLP, SGG, 1825, legajo 4.

37 AHESLP, SGG, 1826, legajo marzo-8.

38 Herrera Canales, op. cit., p. 108.

${ }^{39}$ Estas relaciones se ven en el AHSLP, protocolos de Inst. Púb., 1823:99; 1828:543.

40 En 1824 fueron confiscados a Del Hoyo 19 barras de plata, sebo y unas mulas, todo con un valor de más de 20000 pesos. AHESLP, SGG, 1824. Memoria de Hacienda Pública de la Provincia de 1821, octubre de 1824; protocolos de Inst. Púb., 1824:222. Sin embargo, Del Hoyo era fideicomiso de don Manuel María de Gorriño y Arduengo, rector del Colegio Guadalupano y una de las figuras más respetadas en la capital. IHESLP, protocolos de Inst. Púb., 1823:105. 
oriente de Potosí era suelo fértil. Allí había hacendados deseosos de mandar productos agrícolas directamente a Tampico para exportación. ${ }^{41} \mathrm{Y}$ entre la clase de rancheros y arrendatarios, muchos de ellos militares, el "liberalismo" que atacaba los privilegios señoriales y eclesiásticos estaba muy bien visto. Durante una gira por el oriente del estado, Poinsett había encontrado sentimientos "republicanos" aun en "las rancherías más aisladas". ${ }^{42}$ Allí había estado concentrada la insurgencia durante las guerras de Independencia; en Río Verde estalló la rebelión en 1823 del coronel José Márquez contra el gobierno del estado y en favor del federalismo; y también en 1823 surgió en Huehuetlán un movimiento separatista que proclamó una provincia de las Huastecas. ${ }^{43}$

El puerto de Tampico representaba a la vez oportunidad y amenaza para la elite comercial y política del altiplano. Oportunidad si podía llegar a monopolizar el comercio del gran puerto de Tampico. ${ }^{44}$ Amenaza porque significaría el surgimiento de su "periferia interna", ${ }^{45}$ sobre lo cual tenía poco control o nada. Era una amenaza tanto política como económica, cosa destacada por Ponciano Arriaga quien se refería a Tampico como "una pistola cargada y preparada para descargarse sobre el corazón de San Luis Potosí".46

\section{La producción y el estado}

Con la Clasificación de Rentas del 4 de agosto de 1824 - "la primera piedra del edificio federal",$-{ }^{47}$ el estado podía convertirse en una entidad política con genuino poder económico. El gobierno federal se quedaba con los derechos de exportación e importación, los de acuñación de moneda, y los monopolios de tabaco, sal y pólvora, la lotería, el correo, los derechos sobre la propiedad urbana y rural de la nación, y los impuestos establecidos por el Congreso en los territorios. Todas las demás rentas se quedaban en poder de los estados, las más importantes eran los impuestos sobre la producción de oro y plata, las alcabalas, los diezmos seculares, y la contribucion directa de tres días de trabajo. El gobierno federal, a cambio de estas concesiones a los estados, stableció un contingente o cuota anual, que

41 Los Verástegui desde temprano en el siglo querían un buen camino de Río Verde a Tampico para exportar café. Amerlinck, op. cit., p. 116.

42 Bazant, op. cit., p. 36.

${ }^{43}$ Sobre las guerras de independencia, véase Primo Feliciano Velázquez, Historia de San Luis Potosi, Archivo Histórico del Estado, Academia de Historia Potosina, San Luis Potosí, 1982, t. 3. Sobre la rebelión de Márquez, véase AHEsLP, Intendencia, 1823, legajos 6 y 7; sobre el movimiento en la Huasteca, AHESLP, Intendencia, 1823, legajo 6, "Libro 11 de las Sesiones de la Diputación Provincial", sesíón de 18 de agosto, 1823.

44 En cuanto a volumen de importaciones y exportaciones, Tampico era el segundo puerto en la primera mitad del siglo XIX (después de Veracruz) con un valor anual de comercio de entre dos y cuatro millones. Herrera Canales, op. cit., pp. 120-123.

45 Tutino, op. cit., pp. 216-222, utiliza este término para describir regiones dentro de estados centrales que habían sido olvidadas durante la colonia, pero que empezaron a surgir en el siglo xix. Más que nada se refiere a las tierras calientes de Michoacán, Guerrero, San Luis Potosí y otras. Un excelente estudio del surgimiento de la tierra caliente de Michoacán en la primera mitad del siglo XIX es Gerardo D. Sánchez, El suroeste de Michoacán: estructura económico-social, 1821-51, Universidad Michoacana de San Nicolás de Hidalgo, México, 1979.

46 La Época, periódico oficial del estado de San Luis Potosí, núm. 88, abril 18 de 1847, p. 2

47 Macune, op, cit., p. 81 . 
cada estado tenía que entregar al tesorero nacional. El estado de San Luis tenía que pagar 101250 pesos anuales a la federación, cuatro y medio reales por cada uno de sus 180000 habitantes. Gracias a los préstamos británicos, la federación bajó los contingentes un tercio en 1825 , y hasta la mitad en 1826 para dar a los estados tiempo de arreglar sus haciendas. ${ }^{48} \mathrm{El}$ gasto de los batallones provinciales era la responsabilidad de la federación. Así era que la elite política del estado pensaba tener los fondos necesarios para llevar a cabo su proyecto de desarrollo. Pero, ¿podría dominar las fuerzas productivas y económicas en su estado, de recaudar las rentas que necesitaba para subsistir?

Viendo los ingresos-egresos del estado en los años 1824-28 (apéndice $\mathrm{C}$ ), se entiende por qué este periodo ha sido nombrado "la luna de miel del sistema federal de impuestos". 49 En primer lugar, los ingresos del estado subieron cada año, mientras pagaba menos a la federación a cuenta de contingente y tabaco. Y también había existencias al final de cada año, aunque no muy sustanciales. No obstante estos índices positivos, no todo era de color rosa. Los gastos del estado subían más rápidamente que los ingresos, dejando al estado con una existencia en 1828 de sólo 524 pesos. En vez de abolir las alcabalas, el estado era cada vez más dependiente de ellas. En fin, el registro de sus ingresos y egresos nos puede señalar algunas tendencias sobre la producción y la capacidad recaudadora del estado; pero, para un retrato más fiel, veamos más a fondo dos ramos de producción muy importantes para el estado: la minería y el tabaco.

Minería: La caída en producción oficial de barras de plata y oro en los años de 1804 a 1819 fue rápida y drástica. Entre 1800-04, las minas potosinas producían 13906 barras de plata y 268 barras de oro; entre 1804-19 solamente 5859 de plata y 55 de oro. ${ }^{50}$ Muchas minas estaban "muertas" por problemas de agua o falta de capital. ${ }^{51} \mathrm{La}$ elite política del estado esperaba revivir y aun superar el auge minero de 1790, invitando capital extranjero para formar compañías de minas, creando su propia casa de moneda y siguiendo la política borbónica de librar la minería de impuestos gravosos. Comparados con los derechos borbónicos, los derechos de $3 \%$ sobre la producción de plata y oro, y $3 \%$ de ensaye vigentes en San Luis de 1824-26, representaban un descuento para la mina de más de 100 pesos cada barra de plata. ${ }^{52}$ El gobierno federal eximía de $2 \%$ el derecho de circulación de toda moneda destinada al fomento de la minería y mantenía el descuento en el precio del azogue. La inversión extranjera era menos en San Luis que en Zacatecas, Guanajuato o Pachuca, pero de todos modos causó una renovación del sector minero en el estado, sobre todo en Catorce, donde los ingleses instalaron una bomba de vapor.

No obstante el pequeño boom minero, los ingresos sobre la producción no subieron notablemente. El problema principal era el

48 Para una discusión más completa de la Clasificación de Rentas, véase Macune, op. cit., pp. 74-81.

49 Ibid., p. 82.

${ }^{50}$ AHESI.P, SGG, 1827, legajo enero-5. Correspondencia de la Comisaria General de San Luis Potosí.

${ }^{51}$ AHESI.P, SGiG, 1826, legajo octubre, expediente: "Informe que hago de las Minas, sus Dueños, de su actual estado, de las haciendas de beneficio, de metales. . ." Guadalcázar, 12 de octubre, 1826.

${ }^{52}$ AHESLP, SGG;, 1826, legajo septiembre. Correspondencia de la Comisaría General de San Luis Potosí. 
contrabando. De hecho, una de las razones para la Casa de Moneda en el estado era precisamente para controlar el escape de barras de plata. Desde luego, -muchas estaban saliendo por Tampico y por el norte sin pagar ningunos derechos. Miguel Lerdo de Tejada estimó que el porcentaje del contrabando de metales en la primera mitad del siglo xIx llegaba hasta 1/3 de la producción total, y era en los puertos sin aduanas oficiales, como Tampico, donde el contrabando era mayor. ${ }^{53}$ Esta pérdida perjudicaba tanto a la nación como al estado. Pero además, el estado tenía problemas propios de contrabando. Los mineros estaban llevando sus barras clandestinamente de Catorce a Zacatecas sin pagar los derechos estatales de producción. El tesorero general del estado, Juan Guajardo, en un oficio al gobernador en 1825 echó a este tráfico clandestino la culpa del "miserable y ratero despacho del mes en que sólo han venido 34 barras". ${ }^{54}$ La salida de barras clandestinas a Zacatecas creció a principios de 1827 cuando Zacatecas suspendió el impuesto federal de $2 \%$ sobre circulación de moneda. Este mismo impuesto, establecido en junio de 1822, todavía estaba vigente en San Luis. ${ }^{55}$ En septiembre de 1827, José Antonio Nieto, administrador de Rentas en la capital, presentó los resultados siguientes al Congreso del estado, declarando que el derecho de $2 \%$ "es ilusorio desde que no se exige en el estado de Zacatecas":

$\begin{array}{cc}\text { Año } & \text { Derechos recaudados (e } \\ \text { Oct.-dic. } 1824 & y \text { ctus.) } \\ 1825 & 1729.6 .0 \\ 1826 & 5033.5 .2 \\ \text { Ene.-sep. } 1827 & 5824.3 .4 \\ & 30.56\end{array}$

Aunque el Congreso suspendió el derecho de circulación en el estado en octubre de 1827, no había una mejora significativa en los ingresos de producción. Parece que los mineros de Catorce respondían más a las condiciones del gran ámbito regional que era el centro-norte, que a las exigencias de la elite política de su propio estado. Esa elite era incapaz de detener la salida de plata y, por lo tanto, no podía aprovechar completamente el pequeño boom minero de los años 20.

En cuanto a los ingresos del estado por la minería, tenemos que ver también la categoría ambigua de "depósitos". En 1823, el intendente listó como "depósitos" los comisos de plata y los descuentos de sueldos. ${ }^{57}$ En las Memorias anuales de 1824 y 1825, Guajardo notó que los depósitos "proceden del derecho de minería cobrado en esta tesorería para remitirlo a su tribunal"'. ${ }^{58} \mathrm{O}$ sea que los depósitos eran

5:3 Miguel Lerdo de Tejada, El comercio exterior de México, México, 1850; Tennenbaum, op. cit., p. 25.

54 NI1tsi.P, scic, 1825, legajo 4.

55 El derecho de $2 \%$ sobre circulación fue decretado por Iturbide en 1822 para recaudar fondos para el déficit nacional de 600000 pesos. Aunque la diputación provincial de San Luis Potosí insistió que "debe cesar luego que llene su objeto", este impuesto se quedó vigente en el estado hasta 1827. AHESL.P, Intendencia, 1822, legajo 3, libro 7 de las Sesiones de la Diputación Provincial, sesión 24 de septiembre de 1822.

56 MHESL.P, SGG, 1827, legajo octubre-3. Legislación Potosina, op. cit., p. 181.

57 Ahtsl.p, sc;;, 1824, Memoria de Hacienda Pública de la Provincia de 1821 -octubre de 1824

58 AHESLP, sci;, 1824, "Tanteo, Corte, Visita, y Relación Jurada” sobre Hacienda Pública desde octubre a diciembre, 1824; 1825, "Tanteo Corte, Visita, y Relación Jurada" sobre Hacienda Pública del año 1825. 
fondos federales recaudados por el estado, como el impuesto de circulación y lo recaudado por los monopolios de sal y pólvora. Pero esos fondos por sí no pueden explicar los altos ingresos de los "depósitos". Las Memorias de 1826-28 no tienen notas sobre "depósitos", pero al menos gran parte de ellos deberian de haber correspondido al Tribunal de Minería. En los años de 1824-26, estos depósitos funcionaban como préstamos de la diputación de minería al gobierno del estado, porque el estado no reintegró toda la cantidad depositada. El hecho de que en 1827, el estado gastó más en reintegrar depósitos que en abonos del contingente y tabaco juntos, señala que para la elite política, cumplir con sus prestamistas locales era más importante que cumplir con el gobierno federal. También destaca la dependencia de la elite política de los préstamos del sector minero. Y finalmente, si entre los "depósitos" estaban los comisos de plata, el estado estaba recibiendo al menos un porcentaje de la producción del contrabando. Que el estado se tenía que satisfacer con ingresos indirectos de la minería ayuda a entender la complejidad de la alianza entre los mineros y la elite política en los años $20 .{ }^{59}$

Tabaco: A finales de la época colonial, el estanco de tabaco era uno de los ramos más pingües del virreinato, produciendo 4447486 pesos en 1808. Pero las guerras de independencia hicieron estragos en el estanco, llegando sus rentas a sólo 648147 en $1824 .{ }^{60} \mathrm{El}$ problema no era la caída de producción, al contrario; el problema era el cultivo clandestino de tabaco y la introducción de tabaco importado. En los años de $1821-24$, la producción clandestina de tabaco floreció en la tierra caliente de San Luis Potosí. ${ }^{61}$ En un esfuerzo por contrarrestar la corrupción y restablecer el monopolio, el gobierno federal dio más poderes administrativos a los estados. Desde el 11 de julio de 1823, las diputaciones provinciales podían suspender y nominar gente para los puestos aduaneros. El 11 de febrero de 1824 el Supremo Gobierno dictó que los estados seguirían comprando tabaco de la federación, pero "queda al arbitrio de cada estado expender la rama de su cupo dentro de su territorio en especie o establecer y arreglar sus fábricas para la venta en labrados". ${ }^{62}$ Los estados comprarían de la federación el tabaco en rama al mayoreo ( 8 reales la libra) y lo venderían al menudeo ( 11 reales la libra), quedando la diferencia en manos de los estados.

La elite política del gobierno de San Luis Potosí veía con gran optimismo esta oportunidad. Con la baja producción minera, su proyecto desarrollista necesitaba otra fuente de ingresos, y la fábrica de tabacos representaba otra posibilidad de acumulación. En los años de 1823-28, el gobierno tomó los pasos necesarios para asegurar los ingresos de la renta de tabaco. El primer paso en 1823 era suspen-

59 En algunas instancias, vemos al gobierno del estado defendiendo los derechos de la mineria contra pueblos lindantes. (Allssi.P, scic, 1827, legajo febrero-2, expediente: "Sobre reservas de metales en el Cedral promovido por el C. Antonio Nieto, vecino del Catorce".) Sin embargo, en 1827, la legislatura del estado apropió tierras de la Diputación y abolió sus privilegios judiciales, Legislación potosina, op. cit., pp. 105, 145 .

60 Memoria sobre el estado de la Hacienda Pública. Imprenta del Supremo Gobierno, México, 1825, p. 42.

61 AHLsi.P, sGG;, 1824, "Estado de esta Administración de San Luis Potosí el 31 de agosto de este año de 1824, hecho por el teniente visitador de la Renta Nacional de Tabacos de Valladolid Dn. Rafael Pérez Marañón".

62 AHESLP, SGG, 1824, Recibo del Decreto 20 del Supremo Congreso Mexicano. 
der a Estevan Toscano, el administrador de tabaco, por "irregularidades". ${ }^{63}$ Establecieron la fábrica de tabaco en 1824 con la ayuda financiera de los vecinos de su comercio. ${ }^{64}$ Como parte del esfuerzo para "el mejor arreglo y segura administración de los caudales de la hacienda nacional del estado", Díaz de León estableció en enero de 1825 una administración de rentas en cada cabecera de partido, uniendo las administraciones de alcabala y tabacos. ${ }^{65}$ Como ya hemos visto, la mayoría de estos puestos pertenecian a militares realistas. Para perseguir contrabandistas, el gobierno estableció un resguardo de tabaco: los notorios celadores rurales que alcanzarían su apogeo en los años 30 y 40.

De los ingresos de tabaco dependía el gobierno del estado en los años de 1824-28 (apéndice $C$ ). Estos ingresos subieron cada año y producían gran parte del cargo del estado. Aunque se suponía que las ganancias principales eran para la federación, el porcentaje que el estado mandaba a la federación disminuía cada año. Aunque San Luis era uno de los pocos estados que pagaba su contingente en los años de 1825-27, no podía decir lo mismo del tabaco. En marzo de 1826, debía a la federación a cuenta de tabacos, 116066 pesos. ${ }^{66} \mathrm{Ya}$ por 1827 , las súplicas de la comisaría general de San Luis al gobierno del estado para que mandaran lo debido venían más frecuentemente. Pero a estas súplicas, Guajardo se lamentaba que el estado "no cuenta a la fecha con un solo peso".67 Para 1829, San Luis Potosí tenía la segunda deuda del país después del Estado de México, a cuenta de tabaco: 368742 pesos. ${ }^{68}$ Obviamente, el gobierno federal no tenía éxito recaudando la renta de tabaco en San Luis Potosí.

Pero tampoco la elite política del estado podía aprovechar al máximo su "monopolio" del tabaco. Sus ingresos dependian en su capacidad de hacer que sus ciudadanos se adaptaran al modelo corporativo. Decía el Manifiesto del Congreso de 1824: "Los miembros del estado, como las piezas de una máquina, que con una armonía recíproca tienden todas al mismo fin que dio el autor a su obra, deben procurar con sus respectivas funciones contribuir cada uno a su modo a mantener aquella combinación unida de diversos movimientos, cuyo resorte principal son las leyes bien guardadas y cuyo fin es la prosperidad del estado". ${ }^{69}$

Para la elite política del estado, los contrabandistas de la rama eran unos parásitos sobre el cuerpo político. Desde la Colonia, había cultivo de tabaco en las sierras cerca de Xilitla, pero las autoridades lo aguantaban, 1) porque la producción era para un mercado bastante limitado en un área apartada, y 2) porque sabían que no había

${ }^{63}$ Las "irregularidades" incluían la creación de estanquillos para amigos y para su amante, falta de recoger cortes de caja mensuales, y por la apropiación de tabaco contrabandeado para su uso personal, Mitss.P, Intendencia, 1823, legajo 6, "Libro 10 de las Sesiones de la Diputación Provincial", sesión 2 de septiembre, 1823.

64 AHFSL, SGG, 1824, Correspondencia, agosto y septiembre.

${ }^{65}$ AHkst.p, sGG; 1825, legajo 1 "Expediente sobre reunión provisional de rentas en los partidos del estado".

66 AHESLP, SGGi, 1826, legajo octubre-2, "Expediente relativo a los pedidos de tabaco que se han hecho por el Gob. del estado para la fábrica que se ha establecido".

67 AHESI.P, SC;(;, 1827, legajo diciembre-1, "Expediente relativo a la solicitud que ha hecho a este Gobierno el Comisario Gral. pidiendo se le auxilie por la Tes. Gral. de este estado con las mayores cantidades posibles en abono de lo que adeuda de contingente y tabacos".

${ }^{68}$ Macune, op. cit., p. 113.

69 Márquez, op. cit., p. 20. 
manera de erradicarlo. ${ }^{70}$ Pero ya en los años 20 , su mercado no era tan limitado; pues el tabaco de Xilitla llegaba hasta Guanajuato. A pesar de los esfuerzos del estado contra los cultivos en el oriente, "encargándoles a todas aquellas autoridades procuren por todos los medios posibles el extinguirlos, no se ha podido conseguir ni ahora ni aun en tiempos del gobierno anterior". ${ }^{71}$ Para los cultivadores indígenas, el tabaco rendía más de 60 pesos anuales, mucho más que un empleo de peón o jornalero. ${ }^{72} \mathrm{Y}$ para los comerciantes intermediarios, las ganancias eran mayores todavía. En 1826 el comisario general de San Luis comunicó a Díaz de León:

El contrabando de esta especie se halla propagado en grado superlativo por la feracidad de estos terrenos desde el río de Pánuco hasta Misantla de norte a sur y de oriente a poniente todo lo que ocupa la sierra baja y alta. . . en cuyo ámbito se hallan los partidos de Pueblo Viejo, Chicontepec, Huejutla, Villa de Valles (por la ranchería de Xilitla), Cimapan. . . En todos estos partidos se siembra y se cosecha con abundancia el tabaco y todos lo venden para lo interior de donde baja a comprar a cambio de efectos y de reales, haciéndose de este efecto un comercio excesivo. ${ }^{73}$

Los fielatos y estanquillos de tabaco en San Luis, tanto en el altiplano como en el oriente, se quejaban constantemente del contrabando y de la imposibilidad de controlarlo. El tesorero Guajardo afirmó en junio de 1826 que en San Luis "por tabacos no hay casa ni jacalito donde no haya contrabando". ${ }^{74}$ Vistos como parásitos o "burguesía campesina", 75 los cultivadores de tabaco en la Sierra Gorda, y sus mercaderes, llevaban un comercio activo y fructífero que socavaba el monopolio del tabaco y las ganancias de su fábrica en la ciudad de San Luis Potosí.

Hay que señalar que la amenaza a la elite política que representaba el tabaco clandestino no se originaba en las sierras de Xilitla solamente. De la "cantidad grande" de tabaco decomisado en la provincia en 1823, había tabaco de Orizaba, de la Virginia, "y aun labrados de La Habana". ${ }^{76}$ Entre los comisos del año 1824, había uno de 1375 libras de tabaco de Virginia, y en los casos de comiso de personas “decentes", entre ellos varios comerciantes y militares espa-

70 El visitador Gálvez trató de poner fin a este cultivo, metiendo garitas alcabalatorias en áreas apartadas con mercados internos activos. El resultado fue la violencia de 1767. cuando estalló una rebelión contra la política de alcabalas, en favor de los jesuitas, y que incluía una demanda para la abolición del estanco del tabaco. Rosa Helia Villa de Mebius, San Luis Potosí: una historia compartida, Instituto Mora, México, 1988, pp. 39-40.

71 AHrsi.P, SC; $(,, 1827$, legajo noviembre-3. Correspondencia con otros estados.

72 antsi.P, sci;, 1824, legajo 7, Correspondencia de Xilitla. Sobre sueldos de campesinos en el siglo $\mathrm{xIX}$, véase González Navarro, op. cit., pp. 148-49.

73 MHFSl.P, sCiG, 1826, legajo septiembre-1. Correspondencia de la Comisaría General, 28 de septiembre, 1826 .

${ }^{74}$ Ahtisi.P, SG:G, 1826, legajo junio-2. Correspondencia de Hacienda, 6 de junio, 1826.

75 Franz J. Schryer, “A ranchero economy in northwestern Hidalgo, 1880-1920”, Hispanic American Historical Review, vol. 59,3: 1979, pp. 418-443. Schryer habla de las veredas entre Tamazunchale y Pisaflores que llegaban hasta Querétaro. El noroeste de Hidalgo, donde se encuentra Pisaflores, es parte del espacio regional en torno a Tampico.

76 AHESl.P, Intendencia, 1823, legajo 7, "Libro 11 de las Sesiones de la Diputación Provincial", sesión del 2 de diciembre, 1823. 
ñoles, casi siempre se trataba de tabaco importado. ${ }^{77}$ Obviamente los barcos norteamericanos que salían de Nueva Orleans para Tampico llevaban más que mercancía europea. También había comerciantes en Tampico, probablemente españoles, que traficaban con tabaco cubano. Como no hubo aduana marítima en Tampico hasta 1827, mucho tabaco entraba por el oriente de San Luis Potosí. Por eso, era muy importante para el gobierno del estado tener gente suya en las garitas alcabalatorias a lo largo de los caminos del oriente, así como en el altiplano.

He aquí, tal vez, la prueba más eficaz de la impotencia de la elite política del estado. Ser fiel del tabaco o administrador de rentas, sobre todo en pueblos con mucho comercio, era no sólo prestigioso, sino lucrativo. En vez de recibir un sueldo fijo, un administrador se quedaba con un porcentaje de las rentas recaudadas. Se suponía que estos recaudadores eran agentes del estado, pero solían usar sus puestos para la acumulación privada. Por eso había tanta competencia por estos asientos. ${ }^{78}$ Algunos se habían quedado en las mismas familias por generaciones. ${ }^{79}$ Abundaban los casos de administradores acusados, y a veces suspendidos, por recaudaciones excesivas o participación en el contrabando. Don Leonardo Bear y Mier fue suspendido de su puesto como fiel de tabaco en Armadillo en 1825 por no entregar sus cortes de caja; sin embargo, había recuperado su asiento en 1827. Acusaciones contra gente poderosa como Bear y Mier, Gabriel Barragán o Juan de Noriega casi nunca llegaban a suspensiones, por "falta de pruebas" ${ }^{80}$ Los puestos más lucrativos eran controlados por grandes comerciantes, o directamente o por medio de sus apoderados $y$ fianzas. ${ }^{81}$

La incapacidad de la elite política de controlar sus administradores de rentas era mucho más marcada en el oriente que en el altiplano. El gobierno había llenado estos puestos con militares realistas 1) para no pagarles pensiones y 2) a cambio de su lealtad al estado. Esto está claro en el caso del coronel José Márquez, quien después de su rebelión de 1823, se quedó como administrador de rentas en Gamotes, Río Verde. Asi también empezaron los. cacicazgos en la Huas-

it Mtist.p, scici, 1824, "Estado de esta Administración de San Luis Potosí el 31 de agosto de este año de 1824, hecho por el Tente. Visitador de la Renta Nacional de "I Tabacos de Valladolid, Dn. Rafael Pérez Marañón".

is Cuando se abría un puesto en Hacienda Pública, los interesados tenian que entregar sus solicitudes con currículum, cartas de recomendación y lista de fiadores al Congreso del estado, quienes después de mucha discusión presentarían un candidato al gobernador para confirmación. La competición para puestos altos, como ensayador de la Casa de Moneda, era verdaderamente feroz. NHisi.P, scic, 1824, legajo 7.

i9 Mttist. scic, 1825, Representación de José Francisco Oliden, ex receptor de alcabalas del Valle de San Francisco, 18 de junio, 1825. Juan Antonio de Oliden fue nombrado receptor de esta garita en 1779, puesto que tenía hasta 1812. Su hijo, José Francisco heredó el puesto de su padre y lo tenía hasta 1822 , cuando el puesto fue dado al sobrino de José Francisco, Marcelo Oliden.

so Sobre Bear y Mier, AHtst.P, sc;6, 1926. legajo 1826-1, "El ciudadano Leonardo Bear y Mier se queja contra el Ilmo. C. Consultivo por la suspensión que le hizo de su empleo de fiel de tabacos del Armadillo." Sobre Noriega, scic, 1826, legajo junio 2. Para un caso espléndido, vease" "Diligencias que reservadamente se siguen en el Juzgado Primero del Valle del Maíz en averiguación del contrabando introducido de la casa de Dn. Gabriel Barragán, Adm. de Rentas de este pueblo", sci, 1827, legajo marzo-5.

" Por ejemplo el comerciante español, Emeterio Gómez, era el fiador del administrador de rentas en Armadillo, Miguel López de Nava, AHtsi.P, scic, 1826, legajo diciembre-1. Para otros casos, los protocolos de Instrumentos Públicos, 1822-28. 
teca potosina de Pedro de los Santos y Pablo Jonguitud, dos militares realistas, quienes usaban su poder de recaudación para acumular tierras y poder. ${ }^{82}$ En estos pueblos lejos de la elite política, la soberanía residía en los recaudadores armados quienes manejaban una política que se puede llamar de terrorismo fiscal. Aunque esta política tenía sus aspectos feudales, también los recaudadores de rentas, tanto en el altiplano como en el oriente, usaban su poder para mejorar su posición en los mercados regionales, invirtiendo sus pequeñas extorsiones en tierras de labor con peones, en ganado menor y mayor, y en la usura. Esta tradición llega hasta el siglo $\mathrm{xx}$, como nos enseña Romana Falcón en el caso de Saturnino Cedillo, quien usaba la recaudación de impuestos para controlar su fuerza de trabajo. ${ }^{83}$

Para enfrentar la propagación del tráfico clandestino del tabaco, el único recurso del estado era, o poner más garitas o más celadores rurales. Por falta del dinero necesario para más garitas, dobló el tamaño del resguardo de ocho a 16 hombres en septiembre de $1827 . .^{84}$ Parece que logró algo con esta política. Los ingresos del tabaco subieron, aunque ligeramente, y a finales de 1827 en una ceremonia solemne, el gobernador quemó 1430 libras de tabaco y 10851 cajas de cigarros decomisados por el resguardo. ${ }^{85}$ Pero mientras tanto, el estado se había vuelto un campo de batalla. Hacendados del altiplano y pueblos de indios se quejaban de la violencia, robos y abusos del resguardo. Para combatir los resguardos, los contrabandistas también andaban "bien armados" y controlaban territorios en el oriente. ${ }^{86}$ Grupos armados invadian haciendas recaudadoras de rentas y garitas alcabalatorias. En Tancanhuitz "dos hombres que pasaron con tabaco de contrabando" prendieron fuego a la administración de rentas y la cárcel pública. ${ }^{87}$ Oficiales del gobierno se quejaban mucho en estos años de la desobediencia e insolencia del pueblo. El receptor de rentas del Valle de San Francisco se quejaba sobre todo de las mujeres contrabandistas, que según los registros de comisos, estaban muy activas en el comercio clandestino: "son más acérrimas que los hombres, pues éstas llenan la boca y dicen: 'aunque sigamos ¿qué nos ha de hacer?' y en efecto como nada se les hace, se burlan de uno y éste es el motivo también, para que el contrabandista arriero no pare de acarrear tabaco". 88

La elite política culpaba de esta "anarquía" del campo al hecho de que desafortunadamente los principios de la independencia y la libertad habían sido "mal interpretados por la ignorancia". ${ }^{89}$

\section{Conclusiones}

El 31 de enero de 1824, la entidad político-administrativa que era la provincia de San Luis Potosí se constituyó en un estado "libre y

82 AHESI.P, Intendencia, 1823, legajo 7; sGG, 1827, legajo octubre 3. Véase también Enrique Márquez "Formación y naturaleza de feudos y caciques", en Márquez, op. cit., pp. 404-420.

83 Romana Falcón, Revolución y caciquismo. San Luis Potosí, 1910-1938, El Colegio de México, México, 1984, p. 47.

84 AHEsI.P, SG;i, 1827, legajo septiembre-1.

85 AHESI.P, SG;i, 1827, legajo diciembre-1.

86 AHESLP, SGG, 1827, legajo noviembre-3. Correspondencia de otros estados.

87 AHESL.P, SGG, 1825, legajo 5. Correspondencia de Tancanhuitz.

88 AHESL.P, SGG, 1827, legajo diciembre-4.

${ }^{89}$ Memoria sobre el Estado de la Hacienda Pública, op. cit., p. 39. 
soberano". Pero si una de las pruebas de soberanía de un estado es su capacidad de extraer recursos de sus pueblos y de controlar la resistencia a esta extracción, no estamos frente a una entidad soberana. ${ }^{90}$ Hemos visto en este ensayo lo difícil que era para la elite política hacer del estado una corporación monopolizadora en que todas las ganancias de la producción y del comercio pasaran al epicentro del altiplano, la capital de San Luis. En primer lugar, la parte oriente del estado estaba orientada hacia otro lado, hacia el puerto de Tampico. La constelación de intereses que constituía este otro ámbito regional -incluyendo algunos comerciantes y mineros del altiplano y muchos hacendados, rancheros y pueblos del oriente - no estaba dispuesta a entregar sus recursos al gobierno del estado. En segundo lugar, aun dentro de la economía minero-ganadera del altiplano había comerciantes y mineros orientados más bien al gran ámbito regional del centro-norte de México, y no solamente al ámbito más limitado del altiplano potosino.

Para colmo, frente a toda esta resistencia, la elite política del estado era impotente. Sus burócratas, lejos de usar sus puestos para fomentar el proyecto de la elite, creaban espacios de acumulación privada. Los esfuerzos del estado de cerrar estos escapes terminaban en confrontación y violencia, sobre todo en el oriente. La elite política, no quería o no podía adaptar su economía política, a acomodar los grupos y actividades nuevos que habían surgido con las secuelas de las guerras de independencia. Su proyecto era una versión modificada del mercantilismo borbónico; los grupos que se oponían a esa política habían "malinterpretado" la libertad. El gobierno de Díaz de León terminaría en 1828 a manos de Vicente Romero, yorkino y militar con nexos fuertes en el oriente del estado. La elite política regresaría en 1835, sin Díaz de León, sin su ala "radical", y sin ilusiones de una utopía federalista. Pero su proyecto económico no había sido alterado en lo básico. Queda por determinar si bajo el sistema centralista la elite política logrará dominar las actividades económicas de su territorio administrativo. Pero por los años 20, al menos, parece verdad que el "estado libre y soberano de San Luis Potosí” era poco más que una entidad de dominación ficticia.

90 Fabián de Fonseca y Carlos de Urrutia, Historia general de la Real Hacienda, impresa por Vicente G. Torres, México, 1845, 6 tomos; Fonseca y Urrutia destacaron el carácter "sagrado" del tesoro del estado, "prohibiéndose el tocarlo a toda mano que no sea la soberana" (t. I, p. 1); también Charles Tilly, ed., The formation of national States in western Europe, Princeton University Press, Princeton, 1975, p. 40. 


\section{Apéndice A}

Noticia de los individuos que han sido alcaldes desde el año de ochocientos uno al presente, tanto de primera como de segunda, tercera y cuarta elecciones, no incluyéndose los de los años precedentes a éstos porque hasta el de ochocientos inclusive no había elección del primero sino que el segundo pasaba a serlo.*

Votos

Año de 1801

1 Eugenio Terán

2 Juan Antonio Vildósola

1802

1 Andrés de la Sierra (C-E)

2 Ángel Prieto de la Maza (E)

1803

1 Juan Cos Martínez

2 Juan Antonio Vildósola

1804

1 Miguel Flores (C-E)

2 Dionisio del Castillo

1805

1 Pedro Imaz (C-E)

2 Ignacio Astegui (CR)

$$
\text { - } 1806
$$

1 José Antonio Otaegui (CR)

2 Ignacio Astegui (CR)

1807

1 Francisco García

2 Juan Manuel Prieto

1808

1 Ignacio Astegui (CR)

2 Félix Gorriño

1809

1 Pablo de la Serna (C-E)

2 Juan Gómez (C-E)

1810

1 Eugenio Terán

2 Pedro Barrenechea (C)

1811

1 José María Ontañón

2 Urbano. Malavear (C-E)
Votos

Año de

1812

1 Francisco Díaz

2 Agustín Navedo

\section{3}

1 Ignacio Astegui (CR)

2 Urbano Malavear (C-E)

1814

1 Miguel Flores (C-E)

2 José Pulgar (CR)

1815

1 José Antonio Otaegui (CR)

2 Andrés Pérez Soto (C-E)

1816

1 Ignacio Soria (C-CR)

2 Ramón Martínez del Hoyo

1817

1 Ignacio Astegui (CR)

2 Matías Parra (C-CR)

1818

1 Antonio Frontaura (CR)

2 Välentín Soberón (C)

1819

1 Rarrón Martínez del Hoyo

2 Caye $\_$ano Bracamonte (C-E)

1820

1 Valentín Soberón (C)

2 José Salceda

1821

1 Juan Gómez (C-E)

2 Rafael Villalobos (C-CR)

1822

l Francisco García

1 Joaquín Reynoso (C)

2 Ignacio Astegui (CR)

- Archivo Histórico del estado de San Luis Potosí, Fondo Secretaría General de Gobierno, 1827, legajo noviembre-1. 


\begin{tabular}{|c|c|c|c|}
\hline Votos & $\begin{array}{c}\text { Año de } \\
1801\end{array}$ & Votos & $\begin{array}{c}\text { Año de } \\
1812\end{array}$ \\
\hline & 1823 & & 1826 \\
\hline 1 & Pedro Imaz (C-E) & 1 & Eulogio Esnaurrízar (C-CR) \\
\hline \multirow[t]{4}{*}{2} & Manuel Sánchez (CR) & 2 & Francisco Cabrera (C.CR) \\
\hline & & 3 & Víctor Márquez (CR) \\
\hline & & 3 & Ignacio Lambarri (CR) \\
\hline & $\begin{array}{c}1824 \\
\text { Ignacio Soria (C-CR) }\end{array}$ & 4 & Juan García Diego (CR) \\
\hline 1 & Pantaleón Ipiña (C-E) & & 1827 \\
\hline \multirow[t]{3}{*}{2} & Macario Machuca (C-CR) & 1 & Ignacio Astegui (CR) \\
\hline & & 1 & José Pulgar (CR) \\
\hline & & 1 & Pedro Fernández ( $C-C R$ ) \\
\hline 1 & Rafael Villalobos (C-CR) & 1 & Rafael Villalobos (C.CR) \\
\hline 2 & Pedro Dávalos (C-CR) & 2 & José Ma. Longinos del Día \\
\hline 3 & Manuel Oviedo (C-CR) & 3 & Iuan Leonides Revnoso (C-CR) \\
\hline 4 & Juan Manuel Padilla (CR) & $\begin{array}{l}3 \\
4\end{array}$ & Antonio Escobar (CR) \\
\hline
\end{tabular}

C, comerciante; E, español; CR, criollo 


\section{Apéndice B}

Diputados del Primer Congreso Constituyente 1824-25

Dr. Manuel María Gorriño y Arduengo

Crnl. José Miguel Barragán

Dr. Pedro Ocampo

Pres. José María Guillén

Pres. Rafael Pérez Maldonado

Capt. Manuel Ortiz de Zárate

Capt. José Pulgar

Lic. José Sotela de la Hoyuela

Lic. Antonio Frontaura y Sesma

C. Mariano Escandón

C. José María Núñez de la Torre

C. Ignacio Soria

C. Francisco María Aguirre

Suplentes:

C. Francisco Antonio de los Reyes

Pres. Diego de Bear y Mier

C. Alexandro Zerraton

C. Ignacio López Portillo

Tente. Eufrasio Ramos

Diputados del Segundo Congreso Constituyente 1826

C. Francisco Antonio de los Reyes

Pres. Rafael Pérez Maldonado

Pres. Diego de Bear y Mier •

Tente. Eufrasio Ramos

C. Ignacio López Portillo

Capt. José Pulgar

Dr. Pedro Ocampo

Pres. José María Guillén

C. Mariano Escandón

Cinl. José Miguel Barragán

C. Ignacio Soria - Secretario

Capt. Manuel Oriz de Zárate - Secretario

Diputados del primer Congreso Constitucional 1827-28

Lic. Luis Guzmán - Presidente/vicepresidente

Crnl. Vicente Romero - Vicepresidente/presidente

Dr. Pascual de Aranda - Secretario

Crnl. José Márquez

C. Francisco Condelle

C. José Antonio Taranco

C. José Carlos Torreblanca

C. Manuel Guzmán

C. José Camilo López

C. Juan José Domínguez - Secretario

C. José María Salvatierra - Presidente

C. Fidencio Sierra

C. José María Díaz 


\section{Apéndice $\mathrm{G}$}

Ingresos del estado de San Luis Potosí 1824-1828*

(en pesos)

$\begin{array}{lllll}10 / 24-12 / 24 & 1825 & 1826 & 1827 & 1828\end{array}$

\begin{tabular}{|c|c|c|c|c|c|}
\hline $\begin{array}{l}\text { Existencia del } \\
\text { año anterior }\end{array}$ & 2 & 471.6 & 5217.3 & 1474.1 & 524.4 \\
\hline Plata pasta pura & 7656.4 & 32366.2 & 35094.2 & 37523.4 & 39927.3 \\
\hline Diezmos & - & - & 8000.0 & 32909.1 & 92581.0 \\
\hline Alcabalas & 5580.0 & 61346.5 & 55656.6 & 67129.0 & 107373.5 \\
\hline Tabaco & 7207.3 & 127163.0 & 131038.6 & 165906.5 & 174645.2 \\
\hline Depósitos & 3964.6 & 93606.7 & 128933.0 & 78410.2 & 16685.7 \\
\hline $3 \%$ consumo & 一 & 5595.6 & 13435.0 & 18289.0 & - \\
\hline Otros** & 2405.6 & .11310 .4 & 13475.3 & 29995.1 & 38836.4 \\
\hline Total & 26814.3 & 331860.6 & 390850.4 & 431636.6 & 470574.1 \\
\hline
\end{tabular}

Egresos del estado de San Luis Potosí 1824-1828

\begin{tabular}{|c|c|c|c|c|c|}
\hline Buenas cuentas & 6157.6 & - & - & 一 & 6179.0 \\
\hline Gastos comunes & 11066.2 & 30162.5 & 78629.2 & 111045.2 & 76670.7 \\
\hline Sueldos & 2139.3 & $58 \quad 177.3$ & 77914.7 & 87127.3 & 100783.6 \\
\hline Tabacos & 1000.0 & 20697.5 & 44611.1 & 23570.0 & 21614.3 \\
\hline Depósitos & - & 69939.2 & 75840.2 & 123518.6 & 58286.6 \\
\hline Contingente & 5076.2 & 82377.6 & 68500.0 & 45312.4 & 2408.2 \\
\hline Factoría de Tab. & 一 & 60906.3 & 37798.2 & 33075.4 & 44153.1 \\
\hline Otros*** & 903.0 & 4382.2 & 6082.5 & 7462.6 & 96188.5 \\
\hline Total & 26342.5 & 326643.2 & 389376.3 & 431112.1 & 405284.6 \\
\hline
\end{tabular}

- En estos cálculos, el número después del punto es en reales: 8 reales $=$ un peso. Por ejemplo, $\$ 151.6=151$ pesos y 6 reales. Las fuentes son AHESLP, SGG, Memorias de Hacienda 1824, 1825, 1826, 1827. Memoria del Gobierno del Estado, 1826, Imprenta del Estado, San Luis Potosí, 1829.

* Otros ingresos incluían los de ensaye, plata [. . .] oro, oro incorporado, papel sellado, media annata, pulperías, derecho municipal, fábrica de palacio y otros de menor importancia en estos años.

*** Otros gastos de 1828: milicia cívica, diezmos, préstamo, Casa de Moneda y otros menores. 